Article

\title{
Religious Observance and Well-Being among Israeli Jewish Adults: Findings from the Israel Social Survey
}

\section{Jeff Levin}

Institute for Studies of Religion, Baylor University, One Bear Place \#97236, Waco, TX 76798, USA; E-Mail: jeff_levin@baylor.edu; Tel.: +1-254-710-7555

Received: 26 August 2013; in revised form: 13 September 2013 / Accepted: 18 September 2013 / Published: 27 September 2013

\begin{abstract}
This study reports on analyses of Jewish respondents $(\mathrm{N}=6,056)$ from the 2009 Israel Social Survey. Multivariable methods were used to investigate whether religiously observant Jews have greater physical and psychological well-being. After adjustment for age and other sociodemographic correlates of religion and well-being and for a measure of Israeli Jewish religious identity (i.e., secular, traditional, religious, ultra-Orthodox), two findings stand out. First, greater Jewish religious observance is significantly associated with higher scores on indicators of self-rated health, functional health, and life satisfaction. Second, there is a gradient-like trend such that greater religiousness and life satisfaction are observed as one moves "rightward" across religious identity categories. These findings withstand adjustment for effects of all covariates, including Israeli nativity and Jewish religious identity.
\end{abstract}

Keywords: religion; health; well-being; Judaism; Israel

Abbreviations: ICBS: Israel Central Bureau of Statistics; ISS: Israel Social Survey

\section{Introduction}

The past 20 years or so have seen a rapid expansion of empirical research on religious determinants of well-being, broadly defined, including both physical and psychological dimensions. By now, thousands of studies, reviews, and conceptual and theoretical papers have been published in sociology, psychology, and medical journals, and elsewhere, most pointing to a generally salutary religious influence (see [1]). This overall finding, however, is greatly nuanced, and has a tendency to be overstated and misinterpreted, as researchers in this field have long noted (e.g., [2]). The salience of 
religiousness for well-being - that is, the presence and magnitude of observed effects - has been found to vary depending upon the domain of well-being, the religious construct, and the population under study. There has been considerable research on North American samples of White Protestants, especially on the impact of regular attendance at church services, and a plethora of studies which focus on just one or another measure of global self-assessed health status or psychological well-being. But other topics, measures, and population groups have been less represented, as have studies which investigate multiple outcomes.

A particular emphasis in this literature has been on identifying religious determinants of indicators of mental health and psychological well-being [3]. This includes clinical and community studies of depression [4] and other psychiatric outcomes, including anxiety, psychotic disorders, suicide, and substance abuse [5], as well as studies of various psychosocial outcomes such as self-esteem, mastery or self-efficacy, and control beliefs (e.g., [6]). A substantial group of studies, conducted using older population cohorts and dating back many decades, has focused on developing predictive models of subjective, self-assessed measures of a variety of related constructs, including positive and negative affect, affect balance, happiness, and congruence or life satisfaction. This literature has been especially prominent within the fields of social gerontology and geriatrics, and results have been fairly consistent: greater religiousness, on average, seems to be associated with greater well-being, as defined by these constructs $[7,8]$. Recent efforts to summarize and interpret this work suggest that religion serves to promote well-being by fulfilling several functions, including satisfying ongoing needs for self-transcendence, sociality, control, and meaning [9]; by engendering perceived closeness to God, serving as an orienting and motivating force, and offering religious support and coping resources [10]; by providing social capital [11]; and by fostering development of self-regulatory strength [12].

Within this larger literature, studies of religious correlates and predictors of life satisfaction, for one, especially among older adults reflecting back on their lives, are compelling for the consistency of their findings. Systematic reviews conducted in the 1990s (e.g., [13,14]) had already compiled dozens of such studies dating back to 1980 and published just in the gerontological literature. These showed mostly salutary, or positive, effects of religiousness, variously defined. Such studies actually go back at least as far as the sociological research of Moberg in the early 1950s, who identified religious correlates or predictors of "personal adjustment," an amalgam of indicators of positive affect, congruence, and domain-specific satisfaction (e.g., [15]).

These findings, in turn, are consistent with the results of studies identifying positive religious impacts on subjective self-ratings of health, typically via single-item measures of global or overall health or of functional health or lack of an activity-limiting disability. Including a spate of studies again within gerontology and geriatrics, the most notable program of research on this topic has been the work of Idler, whose investigations of religion and self-rated health (e.g., [16,17]) have been complemented by important conceptual pieces on the self-assessment of health (e.g., [18]), a topic on which she is the leading authority. Throughout such studies, higher levels of religiousness, according to myriad measures, are mostly positively associated with higher scores on items or indices assessing overall health or ambulatory status.

While such findings are generally consistent and well-replicated by now, summarized in numerous reviews, and familiar to behavioral and social researchers, they are, as noted, not without limitations. It would be wrong to presume, without empirical validation, that these results imply universally 
applicable associations regardless of population or of religious or well-being measures. Specifically notable in this literature are the relative paucity of studies that (a) draw on samples from non-Christian populations, (b) investigate this issue outside the U.S., (c) utilize large national probability data sources, and (d) contain multiple indicators of both religiousness and well-being within a respective study. The present study aims to address these concerns through analyses of data from a large national probability survey of the adult Israeli Jewish population conducted recently (in 2009) and containing three indicators of well-being and several measures assessing expressions of Jewish religious observance. The intent here is to extend the literature on this subject to a national and religious population that has been, up to now, relatively underrepresented in this literature.

\section{Judaism and Well-Being}

A small but growing body of existing findings has identified religious correlates of well-being among Jews in both Israel and the diaspora. These include significant impacts on positive affect [19], happiness [20], and life satisfaction [21-23]. More ambiguous results have been observed for explicitly mental-health-related outcomes (e.g., [24-26]). Studies of physical health or rates of morbidity or mortality are even fewer, and based on samples from narrowly defined populations, such as kibbutzim, although results do point to a salutary religious impact (e.g., [27]).

These and several other studies of this type are uniformly interesting, provocative, and well-done but, collectively, they are limited, mostly methodologically, and thus do not permit drawing broader inferences as to the population impact of Jewish religious observance on physical or psychological well-being. The three most substantive limitations are that these studies (a) are mostly not based on large population-wide samples, (b) tend not to examine a multiplicity of well-beingrelated outcomes or focus on any one outcome in great depth, and (c) are limited in their assessment of Jewish religiousness. To be clear, none of these issues signifies a deficiency or misstep in any of these studies; they were just not designed to answer more global questions, or, alternatively, the data required to do so were simply not available.

More recently, two ongoing programs of research have begun to address these limitations, enabling a more indepth examination of whether and how religious observance influences the physical and mental health of Jews. These studies have found that, for the most part, although not unanimously, religious observance appears to be a salutary force in Jewish life, in terms of both physical and psychological dimensions of well-being.

Studies by Rosmarin and colleagues have identified significant impacts of religiousness on a variety of health-related outcomes, primarily among Orthodox and Torah-observant Jews. This work includes studies identifying significant associations between myriad indicators of religious beliefs, attitudes, and practices and various measures of depression and anxiety [20,28-31] and physical health [32,33]. For the most part, these studies point to greater or higher or more frequent religiousness, variously assessed, as a protective factor against psychological distress among religious Jews and as a correlate of well-being. This program of research, including both observational and experimental studies, is based on data from a variety of clinical and community samples, primarily using recruited subjects; plans are currently in place for a longitudinal cohort study of Jewish spirituality and psychological functioning. 
Also ongoing are a series of studies by Levin seeking to investigate putative impacts of Jewish religiousness, broadly defined, on health and well-being outcomes using data from large national probability surveys conducted in Israel and/or in the Jewish diaspora, including the U.S. While nothing akin to a global Jewish health survey has yet been attempted, existing datasets can be used, where requisite measures are present, to explore aspects of this larger issue piece by piece. National population surveys, except in Israel, of course, do not have enough Jews to enable this type of analysis in a reliable fashion, but there is a way around this problem. Jewish social or community surveys in the U.S. typically include a measure or two apiece assessing religiousness, health status, and positive well-being; Jewish health or mental health surveys often include measures of religiousness; and Jewish religious surveys will often include a measure or two of life satisfaction, happiness, or self-rated health. No one such dataset may have everything that is required to capture a religion-well-being relationship in its fullness and across the world's Jewish population, but, collectively, a clear picture can be pieced together.

So far, this project has identified significant effects of Jewish religious observance on self-rated health and presence of an activity-limiting health condition in the U.S. [34], on happiness and life satisfaction in Israel and in the diaspora [35], and on psychological well-being and psychological distress [36], health and well-being [37], happiness [38], and numerous measures of physical and mental health $[39,40]$ in Israel. For the most part, though not exclusively, greater religiousness is associated on average with better health and well-being and less psychological distress. Data for these analyses have come from the National Jewish Population Study; the World Values Survey; the Gallup World Poll; the Survey of Health, Ageing and Retirement in Europe; the European Social Survey; and the International Social Survey Programme.

The present study continues in the tradition of the latter research program, extending this work to another valuable and underutilized data resource, the annual Israel Social Survey (ISS) (see Methods) The ISS is intended to advance social indicators research on quality of life in Israel [41], and these data have been used in the past for analyses of religiosity (e.g., [42]). The 2009 ISS focused specifically on religion, with the addition of a large module of specially designed questions which provided an outstanding opportunity to explore the present subject in the Israeli Jewish population. These data thus enabled an expansion on both of the above streams of research: the studies by Rosmarin and colleagues on Jewish religious influences on well-being outcomes and the work of Levin using large national population-based samples of Jews.

With prior findings as a guide, a couple of general hypotheses can be constructed, with the caveat that previous studies of religion and well-being in this population have used similar but not identical indicators of the constructs under study. First, measures of Jewish religiousness are expected to be positively associated with well-being indicators. That is, both behavioral observance (e.g., synagogue attendance, preserving religious tradition) and pro-observance attitudes (e.g., regarding religious knowledge and importance of Jewish observance) are hypothesized to be associated with greater life satisfaction and better self-assessments of health. Theoretical writing in the larger religion and health field has suggested that greater religiousness may benefit physical and psychological well-being by motivating and reinforcing healthy behavior, encouraging fellowship with co-religionists that offers emotionally and tangibly supportive resources, and engendering salutary emotions, health promoting 
beliefs and attitudes, and hopeful or optimistic expectancies (see [43]). This is supported by an increasing number of empirical studies, as well (see [1,44]).

An observed relationship specifically with measures of physical health status may also result in part from the potential confounding of public religious behavior and ambulation, at least in theory, especially among older adult respondents. This possibility is in keeping with decades of observation in studies of religion and health, although longitudinal analysis of population-based data does point to a substantive health effect of public religious behavior (e.g., [45]). In the present study, there is one measure of public religious behavior (synagogue attendance) and a single-item measure of functional health. While a positive association is anticipated, one way to verify that this association is at least partly substantive is to adjust for effects of age. While this is not a perfect solution, of course-longitudinal data would be ideal, but are not available here - it at least enables ruling out that any putative finding of a significant association between synagogue attendance and health is wholly an artifact of age-related declines in physical function that might limit public religious activity.

Second, it is also hypothesized that well-being, as well as religiousness, will be greater as one moves "rightward" across the familiar Israeli categories of Jewish religious identity and practice (i.e., secular, traditional, religious, ultra-Orthodox). A few studies among both U.S. and Israeli Jews have provided evidence of a modest "dose-response" gradient in the religion-well-being relationship, to use the language of epidemiology. This includes progressively greater psychological well-being in Israel as one moves in the direction of greater observance [36], a substantive effect of religiousness on health indicators in the U.S. primarily among Conservative and Orthodox Jews [34,46], greater physical and mental health following spiritual struggle in the U.S. only among Orthodox Jews [33], and salience of religious beliefs protecting against depression and anxiety in the U.S. primarily among Orthodox Jews [31]. Perhaps it is religion's manifest ability to promote or elicit self-control and self-regulation, such as through systematizing goal selection, promoting self-monitoring, and building a sense a mastery [12], that offers a mechanism for anticipating greater well-being among more religiously observant Jews.

\section{Methods}

\subsection{The 2009 Israel Social Survey}

The data used in these analyses are from the 2009 sample of the Israel Social Survey (ISS), conducted annually since 2002 by the Israel Central Bureau of Statistics (ICBS) and using the Israeli Population Register. The survey population consists of the permanent non-institutional Israeli population, aged 20 and over, along with residents of non-custodial institutions and new immigrants, the latter if present in the country for at least six months. The ISS is a multi-stage probability survey, with $84 \%$ of the 2009 survey sample drawn in single-stage sampling and the remainder in systematic random sampling in a complex two-stage stratified procedure. The desired final sample size each year is 7,500 respondents; in 2009, this required an initial target sample of 9,389 (see [47,48]).

The ISS in an interviewer administered survey, conducted by ICBS personnel using laptop computers and computer-assisted personal interview software. Interviews are conducted in Hebrew, Arabic, or Russian, and last about one hour. Fieldwork for each wave of data collection lasts all year, from January to December. 
The annual social survey instrument consists of two parts: first, a core questionnaire comprising about 100 items on a variety of general topics typical of population-based social surveys; second, a specialized module that varies from year to year. For the 2009 survey, one of the topics was religious observance, which resulted in the inclusion of numerous items on diverse aspects of religious identity and participation. In that year's survey, $81.2 \%$ of the total sample of 7,462 respondents were self-identified as Jewish, resulting in a sample size of 6,056 for the present analyses.

\subsection{Measures}

Analyses utilize single-item variables and scales assessing multiple well-being outcomes, indicators of Jewish religious observance, and sociodemographic covariates. Many of these variables were reverse-coded or recoded in other ways to facilitate analyses.

\subsubsection{Well-Being Outcomes}

Well-being outcomes include standard single-item measures of self-rated health ("How is your health, overall?"; coded as: 1 = not good at all, 2 = not so good, 3 = good, 4 = very good), functional health (combination of responses to "Do you have any physical or health problem [that has lasted six months or more]?" and "Does this problem interfere with your day-to-day functioning?"; coded as: 1 = yes, problem greatly interferes, 2 = yes, problem interferes, $3=$ yes, but problem doesn't interfere so much, $4=$ yes, but problem doesn't interfere at all, $5=$ no problem), and life satisfaction ('Overall, how satisfied are you with your life?"; coded as: $1=$ not satisfied at all, 2 = not very satisfied, $3=$ satisfied, $4=$ very satisfied).

\subsubsection{Religious Indicators}

Religious indicators include single-item self-assessments of Jewish religious knowledge ("How do you assess your level of knowledge on religion and tradition?"; coded: 1 = not good at all, 2 = not so good, 3 = good, 4 = very good) and preserving Jewish religious tradition ("To what extent do you preserve your (Jewish) religious tradition?"; coded: 1 = not at all, 2 = to a small extent, 3 = to a great extent, 4 = to a very great extent), a single-item measure of synagogue attendance (combination of responses to "In the past year, did you go to synagogue?" and "How often do you go to synagogue?"; coded: 1 = never, 2 = only on special occasions, such as celebrations or memorials, $3=$ only on Rosh HaShanah and Yom Kippur, or one of them, $4=$ on holidays, $5=$ almost every Saturday and holidays but not on weekdays, 6 = every day or almost every day, including Shabbat and holidays), and an Importance of Jewish Observance Scale $(\alpha=0.92)$ (summarizing scores for five variables each based on the question, "Is it important that you or your family do the following things?"; the five things being circumcision, aliyah laTorah [reading the Torah] at your bar mitzvah ceremony, a wedding ceremony performed by a rabbi, a religious burial ceremony, and following shiv'ah [mourning] ritual, each coded: 1 = not important at all, $2=$ not so important, $3=$ important, 4 = very important). The range of scores on this scale is from 5 to 20 .

Additional religious items were present in the 2009 ISS dataset, including ones related to sabbath and ritual observance. It was hoped that these would be able to be combined into a couple of summary 
scales, but the survey's strategy of skip patterns prevented this: these particular items were not asked of any of the more than 1,200 Orthodox respondents, and the present investigator was not comfortable presuming that these individuals could be read back into these variables through imputing or force-coding them as the highest category of observance. Thus, these measures were excluded from this paper's analyses.

\subsubsection{Covariates}

Covariates include age (in years), gender $(0=$ male, $1=$ female), marital status $(0=$ not currently married and living together, 1 = currently married and living together), education $(1=1-4$ years of education, $2=5-8$ years of education, $3=9-10$ years of education, $4=11-12$ years of education, $5=13-15$ years of education, $6=16$ or more years of education), and Israeli nativity ( $0=$ born in the diaspora, 1 = born in Israel). Each of these is a well-known correlate of religiousness or well-being or both. Nativity is also an important factor to consider here, as the native-born and immigrant Israeli Jewish populations have been found to differ to some extent in their patterns of psychological distress [49] and life satisfaction [21], for various socioeconomic, cultural, and religious reasons. Adjusting for effects of this variable is thus valuable in ruling out that any putative significant findings may be due in part to the nativity of respondents. Controlling for effects of such a variable has proven useful in previous studies in this literature (e.g., [37,39,40]).

Finally, also included is a measure of Jewish religious identity. This measure is used here as a religious indicator, a grouping variable, and a covariate, depending upon the analysis. The ISS asked, simply, "Do you consider yourself as being:" with five possible response categories following the familiar Israeli schema, now officially sanctioned by the ICBS, coded as an ordinal-like measure for the present analyses: 1 = non-religious, secular (lo dati, hiloni), 2 = traditional but not so religious (masorti lo kol kach dati), 3 = traditional but religious (masorti dati), $4=$ religious (dati), $5=$ ultra - Orthodox (haredi). This is similar to the schema used in the Gallup World Poll [36], except that in the present data masorti is divided into two subcategories, reflecting the new ICBS standard (see [50]).

\subsection{Data Analysis}

All analyses were conducted using SAS version 9.2. First, descriptive statistics (means and standard deviations) and bivariate Pearson (r) correlations for all study variables were obtained using the UNIVARIATE and CORR procedures, respectively. Second, differences in study measures by categories of Jewish religious identity were assessed through one-way ANOVA using the GLM procedure. Third, a strategy of hierarchical OLS regression was used to model each of the three well-being indicators, separately, onto the study variables. In Model I, each respective outcome was regressed onto the four religious measures; in Model II, the five sociodemographic variables were added; and in Model III, the ordinal measure of Jewish religious identity was added. These analyses were conducted using the REG procedure. Both standardized $(\beta)$ and unstandardized (b) regression coefficients are reported, in order to enable comparison of associations both within and among models of respective well-being indicators.

This strategy enables examination of each religious measure's putative impact on multiple well-being outcomes in multiple situations: first, bivariately (via correlations); second, multivariably in 
the presence of the other three respective religious measures (Model I); and, third, multivariably after hierarchically controlling for covariates (Models II and III). Given the inherent limitations of a prevalence-study (cross-sectional) design, this approach offers the fullest possible look at the associations between religious exposures and well-being outcomes in the ISS data.

\section{Results}

In Table 1, results are presented for bivariate associations among all study variables. A few key findings emerge. First, not surprisingly, all three well-being outcomes are strongly intercorrelated, as are all four of the primary Jewish religious measures. Second, more interestingly, 11 of the 12 associations among the religious measures and well-being indicators are statistically significant, such that greater religiousness is associated with greater well-being. Third, Israeli nativity is significantly associated with 11 study variables, such that native-born Israelis report better well-being and are more religious, younger, proportionately more male, and better educated than immigrants. Fourth, each sociodemographic variable, in turn, is significantly associated with multiple well-being and religious indicators. Finally, as one moves "rightward" on the ordinal measure of Jewish religious identity, there are significant associations with two well-being outcomes, all of the religious measures, and four sociodemographic variables. Taken together, these findings support use of the sociodemographic variables, nativity, and Jewish identity as covariates in the multivariable analyses.

The ANOVA results, in Table 2, reveal statistically significant differences in every study measure by Jewish religious identity. The large sample size has something to do with that (at least as far as the p-values), but there are clear substantive findings that can be observed. Haredi (ultra-Orthodox) Jews are more religious, naturally, across the board, but also have the highest scores for self-rated health and life satisfaction (and for functional health they are in a close tie with hiloni [secular] Jews). Moreover, there appears to be something of a gradient, at least roughly, as observed in prior studies, such that haredim exhibit better well-being than datim (religious Jews), masortim (traditional Jews), and hilonim, although distinctions among the latter groups appear to be minimal. For religious observance, not surprisingly, there is a clearly visible "dose-response" gradient for every measure: greater religiousness is found, category for category, as one moves to the right. Haredim also tend to be younger, more educated, and more likely to be married and native-born. These results again reinforce the need to adjust for Jewish religious identity in the subsequent analyses. Another interesting finding: even among self-described non-religious Jews, there is still substantial endorsement of the importance of Jewish life-cycle observances.

Table 3 presents the results of the regressions of each of the three well-being outcomes, separately, onto the other study variables. Three of the four religious measures exhibit modest but significant net associations (i.e., in Model III) with one or more well-being outcomes. The measure of Jewish religious knowledge is positively associated with each outcome, even after adjusting for the other respective religious measures and for the covariates, including sociodemographic variables, nativity, and Jewish identity. That is, the greater one's assessment of their knowledge of Jewish religion and tradition, the better they rate their health $(\beta=0.09, p<0.001)$, the less disability they report $(\beta=0.04$, $p<0.001)$, and the greater their life satisfaction $(\beta=0.09, p<0.001)$. 
Table 1. Descriptive statistics and Pearson correlations for study variables.

\begin{tabular}{|c|c|c|c|c|c|c|c|c|c|c|c|c|c|c|}
\hline Study Variables & 1 & 2 & 3 & 4 & 5 & 6 & 7 & 8 & 9 & 10 & 11 & 12 & Mean & sd \\
\hline 1. Self-Rated Health & & & & & & & & & & & & & 3.22 & 0.88 \\
\hline 2. Functional Health & $0.74^{\mathrm{c}}$ & & & & & & & & & & & & 3.96 & 1.47 \\
\hline 3. Life Satisfaction & $0.41^{\mathrm{c}}$ & $0.31^{\mathrm{c}}$ & & & & & & & & & & & 3.17 & 0.69 \\
\hline 4. Religious Knowledge & $0.19^{\mathrm{c}}$ & $0.11^{\mathrm{c}}$ & $0.21^{\mathrm{c}}$ & & & & & & & & & & 2.84 & 0.77 \\
\hline 5. Religious Tradition & $0.10^{\mathrm{c}}$ & $0.05^{\mathrm{c}}$ & $0.20^{\mathrm{c}}$ & $0.48^{\mathrm{c}}$ & & & & & & & & & 2.80 & 0.88 \\
\hline 6. Synagogue Attendance & $0.11^{\mathrm{c}}$ & $0.07^{\mathrm{c}}$ & $0.17^{\mathrm{c}}$ & $0.41^{\mathrm{c}}$ & $0.63^{c}$ & & & & & & & & 3.01 & 1.73 \\
\hline 7. Jewish Observance & $0.05^{\mathrm{c}}$ & 0.02 & $0.14^{\mathrm{c}}$ & $0.34^{\mathrm{c}}$ & $0.58^{c}$ & $0.49^{\mathrm{c}}$ & & & & & & & 17.81 & 3.45 \\
\hline 8. Age & $-0.56^{\mathrm{c}}$ & $-0.45^{\mathrm{c}}$ & $-0.26^{\mathrm{c}}$ & $-0.15^{\mathrm{c}}$ & $-0.12^{\mathrm{c}}$ & $-0.12^{\mathrm{c}}$ & $-0.10^{\mathrm{c}}$ & & & & & & 5.67 & 3.23 \\
\hline 9. Female & $-0.07^{\mathrm{c}}$ & $-0.04^{b}$ & $-0.04^{\mathrm{c}}$ & $-0.04^{b}$ & -0.01 & $-0.23^{c}$ & 0.01 & $0.05^{\mathrm{c}}$ & & & & & 0.52 & 0.50 \\
\hline 10. Married & 0.01 & $0.03^{\mathrm{a}}$ & $0.12^{\mathrm{c}}$ & $0.06^{\mathrm{c}}$ & $0.12^{c}$ & $0.12^{\mathrm{c}}$ & $0.08^{c}$ & $0.21^{\mathrm{c}}$ & $-0.06^{\mathrm{c}}$ & & & & 0.62 & 0.49 \\
\hline 11. Education & $0.33^{c}$ & $0.26^{\mathrm{c}}$ & $0.16^{\mathrm{c}}$ & $0.06^{\mathrm{c}}$ & $-0.05^{\mathrm{c}}$ & -0.00 & $-0.13^{\mathrm{c}}$ & $-0.21^{\mathrm{c}}$ & -0.01 & $0.12^{\mathrm{c}}$ & & & 4.94 & 1.14 \\
\hline 12. Israeli Nativity & $0.42^{\mathrm{c}}$ & $0.30^{\mathrm{c}}$ & $0.23^{\mathrm{c}}$ & $0.20^{\mathrm{c}}$ & $0.15^{c}$ & $0.11^{\mathrm{c}}$ & $0.11^{\mathrm{c}}$ & $-0.48^{\mathrm{c}}$ & $-0.05^{\mathrm{c}}$ & -0.01 & $0.19^{\mathrm{c}}$ & & 0.59 & 0.49 \\
\hline 13. Jewish Identity & $0.05^{\mathrm{c}}$ & 0.02 & $0.17^{\mathrm{c}}$ & $0.46^{\mathrm{c}}$ & $0.69^{c}$ & $0.71^{\mathrm{c}}$ & $0.47^{\mathrm{c}}$ & $-0.10^{\mathrm{c}}$ & -0.02 & $0.15^{\mathrm{c}}$ & $-0.03^{\mathrm{a}}$ & $0.09^{c}$ & 2.19 & 1.31 \\
\hline
\end{tabular}

$$
{ }^{\mathrm{a}} p<0.05 ;{ }^{\mathrm{b}} p<0.01 ;{ }^{\mathrm{c}} p<0.001 \text {. }
$$

Table 2. ANOVA results for study variables, by Jewish religious identity.

\begin{tabular}{|c|c|c|c|c|c|c|c|}
\hline \multirow[t]{2}{*}{ Study Variables } & $\begin{array}{c}\text { Hiloni } \\
\text { (secular) }\end{array}$ & $\begin{array}{l}\text { Masorti Lo Kol Kach Dati } \\
\text { (traditional non-religious) }\end{array}$ & $\begin{array}{c}\text { Masorti Dati } \\
\text { (traditional religious) }\end{array}$ & $\begin{array}{c}\text { Dati } \\
\text { (religious) }\end{array}$ & $\begin{array}{c}\text { Haredi } \\
\text { (ultra-Orthodox) }\end{array}$ & \multirow[t]{2}{*}{$\mathbf{F}$} & \multirow[t]{2}{*}{$p$} \\
\hline & Mean (sd) & Mean (sd) & Mean (sd) & Mean (sd) & Mean (sd) & & \\
\hline Self-Rated Health & $3.25(0.85)$ & $3.13(0.91)$ & $3.08(0.96)$ & $3.20(0.91)$ & $3.62(0.70)$ & 35.65 & $<0.0001$ \\
\hline Functional Health & $4.40(1.40)$ & $3.78(1.53)$ & $3.75(1.60)$ & $3.90(1.48)$ & $4.44(1.17)$ & 25.61 & $<0.0001$ \\
\hline Life Satisfaction & $3.11(0.68)$ & $3.10(0.70)$ & $3.14(0.71)$ & $3.30(0.67)$ & $3.58(0.59)$ & 59.46 & $<0.0001$ \\
\hline Religious Knowledge & $2.51(0.78)$ & $2.82(0.66)$ & $3.08(0.54)$ & $3.25(0.58)$ & $3.65(0.51)$ & 409.85 & $<0.0001$ \\
\hline Religious Tradition & $2.17(0.70)$ & $2.85(0.64)$ & $3.34(0.57)$ & $3.63(0.51)$ & $3.90(0.32)$ & 1491.47 & $<0.0001$ \\
\hline Jewish Observance & $15.69(4.05)$ & $18.76(2.31)$ & $19.63(1.28)$ & $19.73(0.99)$ & $20.00(0.00)$ & 589.49 & $<0.0001$ \\
\hline Age & $5.77(3.24)$ & $5.93(3.25)$ & $5.92(3.19)$ & $5.62(3.26)$ & $3.96(2.65)$ & 39.67 & $<0.0001$ \\
\hline Female & $0.52(0.50)$ & $0.53(0.50)$ & $0.55(0.50)$ & $0.48(0.50)$ & $0.48(0.50)$ & 2.75 & 0.03 \\
\hline Married & $0.57(0.49)$ & $0.58(0.49)$ & $0.66(0.48)$ & $0.70(0.46)$ & $0.82(0.38)$ & 36.97 & $<0.0001$ \\
\hline Education & $5.11(1.04)$ & $4.75(1.20)$ & $4.49(1.20)$ & $4.92(1.26)$ & $5.33(0.85)$ & 72.11 & $<0.0001$ \\
\hline Israeli Nativity & $0.57(0.49)$ & $0.58(0.49)$ & $0.56(0.50)$ & $0.60(0.49)$ & $0.82(0.38)$ & 30.16 & $<0.0001$ \\
\hline
\end{tabular}


Table 3. Regressions of well-being outcomes on Jewish religious indicators.

\begin{tabular}{|c|c|c|c|c|c|c|}
\hline \multirow[t]{3}{*}{ Study Measures } & \multicolumn{3}{|c|}{ Self-Rated Health } & \multicolumn{3}{|c|}{ Functional Health } \\
\hline & I & II & III & $\mathbf{I}$ & II & III \\
\hline & $\beta$ (b) se & $\beta$ (b) se & $\beta$ (b) se & $\beta$ (b) se & $\beta$ (b) se & $\beta$ (b) se \\
\hline Religious Knowledge & $0.17(0.20)^{\mathrm{c}} 0.02$ & $0.08(0.10)^{\mathrm{c}} 0.01$ & $0.09(0.11)^{\mathrm{c}} 0.01$ & $0.10(0.19){ }^{\mathrm{c}} 0.03$ & $0.03(0.06)^{\mathrm{a}} 0.03$ & $0.04(0.07)^{\mathrm{b}} 0.03$ \\
\hline Religious Tradition & $0.01(0.01) 0.02$ & $-0.00(-0.00) 0.02$ & $0.03(0.03) 0.02$ & $-0.01(-0.02) 0.03$ & $-0.02(-0.04) 0.03$ & $0.00(0.00) 0.03$ \\
\hline Synagogue Attendance & $0.04(0.02)^{\mathrm{b}} 0.01$ & $-0.00(-0.00) 0.01$ & $0.04(0.02)^{b} 0.01$ & $0.05(0.04)^{b} 0.01$ & $0.01(0.01) 0.01$ & $0.04(0.04)^{\mathrm{a}} 0.02$ \\
\hline Jewish Observance & $-0.03(-0.01)^{\mathrm{a}} 0.00$ & $-0.01(-0.00) 0.00$ & $-0.01(-0.00) 0.00$ & $-0.03(-0.01) 0.01$ & $-0.01(-0.01) 0.01$ & $-0.01(-0.01) 0.01$ \\
\hline Age & & $-0.45(-0.12)^{\mathrm{c}} 0.00$ & $-0.45(-0.12)^{\mathrm{c}} 0.00$ & & $-0.39(-0.18)^{\mathrm{c}} 0.01$ & $-0.39(-0.18)^{\mathrm{c}} 0.01$ \\
\hline Female & & $-0.03(-0.05)^{\mathrm{b}} 0.02$ & $-0.02(-0.04) 0.02$ & & $-0.00(-0.01) 0.03$ & $0.00(0.01) 0.04$ \\
\hline Married & & $0.07(0.14)^{\mathrm{c}} 0.02$ & $0.08(0.15)^{\mathrm{c}} 0.02$ & & $0.09(0.27)^{c} 0.04$ & $0.09(0.28)^{\mathrm{c}} 0.04$ \\
\hline Education & & $0.19(0.15)^{\mathrm{c}} 0.01$ & $0.19(0.15)^{\mathrm{c}} 0.01$ & & $0.15(0.19)^{\mathrm{c}} 0.02$ & $0.15(0.19)^{\mathrm{c}} 0.02$ \\
\hline Israeli Nativity & & $0.15(0.26)^{\mathrm{c}} 0.02$ & $0.14(0.26)^{\mathrm{c}} 0.02$ & & $0.08(0.23)^{\mathrm{c}} 0.04$ & $0.08(0.23)^{\mathrm{c}} 0.04$ \\
\hline Jewish Identity & & & $-0.10(-0.07)^{\mathrm{c}} 0.01$ & & & $-0.07(-0.08)^{\mathrm{c}} 0.02$ \\
\hline $\mathrm{F}$ & 53.50 & 403.34 & 369.19 & 17.40 & 202.44 & 183.52 \\
\hline $\mathrm{p}$ & $<0.0001$ & $<0.0001$ & $<0.0001$ & $<0.0001$ & $<0.0001$ & $<0.0001$ \\
\hline $\mathrm{R}^{2}$ & 0.04 & 0.38 & 0.39 & 0.01 & 0.24 & 0.24 \\
\hline
\end{tabular}

\begin{tabular}{|c|c|c|c|}
\hline \multirow[t]{3}{*}{ Study Measures } & \multicolumn{3}{|c|}{ Life Satisfaction } \\
\hline & I & II & III \\
\hline & $\beta(b)$ se & $\beta$ (b) se & $\beta$ (b) se \\
\hline Religious Knowledge & $0.13(0.12)^{\mathrm{c}} 0.01$ & $0.09(0.08)^{\mathrm{c}} 0.01$ & $0.09(0.08)^{\mathrm{c}} 0.01$ \\
\hline Religious Tradition & $0.11(0.08)^{\mathrm{c}} 0.01$ & $0.10(0.08)^{\mathrm{c}} 0.01$ & $0.10(0.08)^{\mathrm{c}} 0.02$ \\
\hline Synagogue Attendance & $0.04(0.02)^{\mathrm{a}} 0.01$ & $0.00(0.00) 0.01$ & $0.01(0.00) 0.01$ \\
\hline Jewish Observance & $0.01(0.00) 0.00$ & $0.03(0.01) 0.00$ & $0.02(0.01) 0.00$ \\
\hline Age & & $\begin{array}{c}-0.21(-0.04)^{\mathrm{c}} \\
0.00\end{array}$ & $-0.21(-0.04)^{\mathrm{c}} 0.00$ \\
\hline Female & & $-0.02(-0.02) 0.02$ & $-0.02(-0.02) 0.02$ \\
\hline Married & & $0.13(0.18)^{\mathrm{c}} 0.02$ & $0.13(0.18)^{\mathrm{c}} 0.02$ \\
\hline Education & & $0.09(0.05)^{\mathrm{c}} 0.01$ & $0.09(0.05)^{\mathrm{c}} 0.01$ \\
\hline Israeli Nativity & & $0.07(0.10)^{\mathrm{c}} 0.02$ & $0.07(0.10)^{\mathrm{c}} 0.02$ \\
\hline Jewish Identity & & & $-0.00(-0.00) 0.01$ \\
\hline $\mathrm{F}$ & 89.01 & 105.88 & 94.94 \\
\hline $\mathrm{p}$ & $<0.0001$ & $<0.0001$ & $<0.00001$ \\
\hline $\mathrm{R}^{2}$ & 0.06 & 0.14 & 0.14 \\
\hline
\end{tabular}


The measure of preserving Jewish religious tradition is likewise positively associated with life satisfaction $(\beta=0.10, p<0.001)$, and more frequent synagogue attendance is associated with both self-rated $(\beta=0.04, p<0.001)$ and functional $(\beta=0.04, p<0.001)$ health, all at the net level. Notably, these results are age-adjusted and control for effects of all other religious variables and covariates. Synagogue attendance also exhibits a gross association (i.e., in Model I) with life satisfaction, but this does not withstand taking into account the effects of covariates, the strongest of which is age. The Importance of Jewish Observance Scale is not associated with any outcome at the net level.

\section{Discussion}

To summarize, these results point to a modest but statistically significant association between measures of Jewish religious observance and indicators of well-being. While the effect sizes are not large, they are mostly consistent and withstand adjustment for effects of a variety of pertinent constructs. The most consistent finding is for religious knowledge, the effects of which also appear stronger than those of synagogue attendance. A higher self-assessment of one's level of knowledge about Jewish religion and tradition predicts greater well-being, regardless of the type of Jew that one self-identifies as. This holds true for indicators of physical health as well as for overall life satisfaction. Preserving Jewish tradition, as well, including synagogue participation, matters for life satisfaction and health, respectively. Rephrased in reverse, in epidemiologic fashion, less knowledge and engagement of Judaism appears to be a risk factor for poorer well-being, notwithstanding the limitations of prevalence-study designs in this regard. One cannot help but be reminded here of the famous verse from the prophets: "My people are destroyed for lack of knowledge" (Hosea 4:6).

Limitations, already spoken of, include the cross-sectional design of the ISS, which inhibits inference of epidemiologic risk and protection from these findings, and the nuances of the study variables. Psychological well-being is a multidimensional construct — a meta-construct, really—and validated measures are available for numerous dimensions, including life satisfaction (see, e.g., [51]). The single-item approach used in this study, on the other hand, is commonplace, including in the religion and well-being literature, and has produced findings here that are at least consistent with prior research, including among Jews. The same holds true for the two indicators of health status: better measures exist, but the findings obtained in this study are consistent with results of prior studies using similar variables in other (non-Jewish) religious populations.

Another limitation, although one not typically thought of as such, is the very large sample size, which may lead one to overinterpret statistically significant findings. The structural models for both health outcomes explain very little variance when just accounting for religious effects. Such effects are considerably stronger on life satisfaction, especially due to religious knowledge and tradition.

In sum, this study's posited hypotheses are thus partly confirmed. First, three of the four religious measures (four of the five, if including the Jewish religious identity variable) are significantly associated at the net level with one or more of the well-being outcomes. Moreover, at least as far as can be controlled for in the present study, it does not appear that this result is due to age-related declines in public religious behavior being confounded with physical health. Sufficient adjustments seem to rule this out and, anyway, there are significant religious associations with life satisfaction, as well as health. Second, the hypothesized gradient in well-being and other study variables, by categories 
of Jewish religious identity, is marginally observed. Religious and ultra-Orthodox Jews are more religiously observant than traditional and secular Jews, naturally, but, more to the point, they report greater life satisfaction and, for the ultra-Orthodox, better health. A distinctly dose-response-like gradient, however, in epidemiologic terms, is not observed - secular Jews report comparable or greater health than non-haredi Jews.

For this subject, and this literature, an idealized next step would be to combine the conceptual depth of the original studies by Rosmarin and colleagues - in terms of both religious measurement and psychological and mental health assessment — and the methodological features of Levin's series of population-based studies using existing national probability data. That is easier said than done, however, because unless and until a global or national (U.S.) Jewish health survey is conducted the requisite data points simply do not exist. Multiple Israeli datasets have been utilized so far, but, besides a couple of papers from the National Jewish Population Survey [34,46], no other analyses that are national in scope are possible in the U.S. The presence of numerous community probability surveys of recent vintage, such as in New York, Philadelphia, Boston, and Chicago, point to another possible data resource for investigating these issues, provided that sufficient measures of health and/or well-being are included. The situation may be more optimistic in the U.K. or Canada (or may not be), but there are no nations in the world besides Israel whereby existing general population surveys will likely contain enough Jewish respondents to enable stable population estimates of patterns and determinants of health and well-being. Multidisciplinary and cross-national collaborations among Israeli and diaspora sociologists, epidemiologists, psychologists, and physician-researchers may be the best means to bring a global effort to pass.

\section{Conclusions}

Using data from the 2009 Israel Social Survey, analyses found that Jewish religious observance is significantly associated with greater well-being among Israeli adults. Selected religious indicators are associated with greater life satisfaction and with two measures of health status. Moreover, for life satisfaction, a modest gradient is observed, such that higher scores are found as one moves "rightward" across categories of Jewish religious identity, with datim and haredim reporting the greatest well-being. Haredim also have the highest self-ratings of health. Analyses were adjusted for age and for effects of other sociodemographic variables, including Israeli nativity.

\section{Acknowledgements}

The author would like to thank the Israel Social Sciences Data Center (ISDC) at Hebrew University for graciously providing access to the Israel Social Survey data. He would also like to thank Lea Steele for assistance with computer software and data management.

\section{Conflicts of Interest}

The author declares no conflict of interest. 


\section{References}

1. Harold G. Koenig, Dana E. King, and Verna Benner Carson. Handbook of Religion and Health, 2nd ed. New York: Oxford University Press, 2012.

2. Jeffrey S. Levin. "How religion influences morbidity and health: Reflections on natural history, salutogenesis and host resistance." Social Science and Medicine 43 (1996): 849-64.

3. Jeff Levin. "Religion and mental health: Theory and research." International Journal of Applied Psychoanalytic Studies 72 (2011): 102-15.

4. Timothy B. Smith, Michael E. McCullough, and Justin Poll. "Religiousness and depression: Evidence for a main effect and the moderating influence of stressful life events." Psychological Bulletin 129 (2003): 614-36.

5. Harold G. Koenig. "Research on religion, spirituality, and mental health: A review." Canadian Journal of Psychiatry 54 (2009): 283-91.

6. Neal Krause. "God-mediated control and psychological well-being in late life." Research on Aging 27 (2005): 136-64.

7. Jeffrey S. Levin, and Linda M. Chatters. "Research on Religion and Mental Health: An Overview of Empirical Findings and Theoretical Issues." In Handbook of Religion and Mental Health. Edited by Harold G. Koenig. San Diego: Academic Press, 1998, pp. 33-62.

8. Jeff Levin, and Linda M. Chatters. "Religion, aging, and health: Historical perspectives, current trends, and future perspectives." Journal of Religion, Spirituality, and Aging 20 (2008): 153-72.

9. Neal Krause. "Religion and health: Making sense of a disheveled literature." Journal of Religion and Health 50 (2011): 20-35.

10. Peter C. Hill, and Kenneth I. Pargament. "Advances in the conceptualization and measurement of religion and spirituality: Implications for physical and mental health research." American Psychologist 58 (2003): 64-74.

11. Joanna Maselko, Cayce Hughes, and Rose Cheney. "Religious social capital: Its measurement and utility in the study of social determinants of health." Social Science and Medicine 73 (2011): 759-67.

12. Michael E. McCullough, and Brian L.B. Willoughby. "Religion, self-regulation, and self-control: Associations, explanations, and implications." Psychological Bulletin 135 (2009): 69-93.

13. Harold G. Koenig, ed. Research on Religion and Aging: An Annotated Bibliography. Westport: Greenwood Press, 1995, pp. 33-47.

14. Jeffrey S. Levin. "Religious research in gerontology, 1980-1994: A systematic review." Journal of Religious Gerontology 10, no 3 (1997): 3-31.

15. David O. Moberg. "Church membership and personal adjustment in old age." Journal of Gerontology 8 (1953): 207-11.

16. Ellen L. Idler. "Religious involvement and the health of the elderly: Some hypotheses and an initial test." Social Forces 66 (1987): 226-38.

17. Ellen L. Idler. "Religion, health, and nonphysical senses of self." Social Forces 74 (1995): 683-704.

18. Ellen L. Idler, and Yael Benyamini. "Self-rated health and mortality: A review of twenty-seven community studies.” Journal of Health and Social Behavior 38 (1997): 21-37. 
19. Kate Miriam Loewenthal, Andrew K. MacLeod, Vivienne Goldblatt, Guy Lubitsh, and John D. Valentine. "Comfort and joy? Religion, cognition, and mood in Protestants and Jews under stress." Cognition and Emotion 14 (2000): 355-74.

20. David H. Rosmarin, Kenneth I. Pargament, and Annette Mahoney. "The role of religiousness in anxiety, depression and happiness in a Jewish community sample: A preliminary investigation." Mental Health Religion \& Culture 12 (2009): 97-113.

21. Karin Amit. "Determinants of life satisfaction among immigrants from Western countries and from the FSU in Israel." Social Indicators Research 96 (2010): 515-34.

22. Itzhak Levav, Robert Kohn, and Miriam Billig. "The protective effect of religiosity under terrorism." Psychiatry 71 (2008): 46-58.

23. Tamar Shkolnik, Chava Weiner, Lea Malik, and Yoel Festinger. "The effect of Jewish Religiosity of elderly Israelis on their life satisfaction, health, function and activity." Journal of Cross Cultural Gerontology 16 (2001): 201-19.

24. Ofra Anson, Arieh Levenson, Benyamin Maoz, and Dan Y. Bonneh. "Religious community, individual religiosity, and health: A tale of two kibbutzim." Sociology 25 (1991): 119-32.

25. Amir Shmueli. "Health and religiosity among Israeli Jews." European Journal of Public Health 17 (2006): 104-11.

26. Noa Vilchinsky, and Shlomo Kravetz. "How are religious belief and behavior good for you? An investigation of mediators relating religion to mental health in a sample of Israeli Jewish students." Journal for the Scientific Study of Religion 44 (2005): 459-71.

27. Jeremy D. Kark, Galia Shemi, Yechiel Friedlander, Oz Martin, Orly Manor, and S.H. Blondheim. "Does religious observance promote health? Mortality in secular vs. religious kibbutzim in Israel." American Journal of Public Health 86 (1996): 341-46.

28. Steven Pirutinsky, David H. Rosmarin, Kenneth I. Pargament, and Elizabeth Midlarsky. "Does negative religious coping accompany, precede, or follow depression among Orthodox Jews?" Journal of Affective Disorders 132 (2001): 401-05.

29. David H. Rosmarin, Elizabeth J. Krumrei, and Gerhard Andersson. "Religion as a predictor of psychological distress in two religious communities." Cognitive Behaviour Therapy 38 (2009): $54-64$.

30. David H. Rosmarin, Elizabeth J. Krumrei, and Kenneth I. Pargament. "Do gratitude and spirituality predict psychological distress?" International Journal of Existential Psychology \& Psychotherapy 3 (2010): 1-5.

31. David H. Rosmarin, Steven Pirutinsky, Kenneth I. Pargament, and Elizabeth J. Krumrei. “Are religious beliefs relevant to mental health among Jews?" Psychology of Religion and Spirituality 1 (2009): 180-90.

32. Steven Pirutinsky, David H. Rosmarin, Cheryl Holt, Robert H. Feldman, Lee S. Caplan, Elizabeth Midlarsky, and Kenneth I. Pargament. "Does social support mediate the moderating effect of intrinsic religiosity on the relationship between physical health and depressive symptoms among Jews?" Journal of Behavioral Medicine 34 (2011): 489-96.

33. David H. Rosmarin, Kenneth I. Pargament, and Kevin J. Flannelly. "Do spiritual struggles predict poorer physical/mental health among Jews?" International Journal for the Psychology of Religion 19 (2009): 244-58. 
34. Jeff Levin. "Health impact of Jewish religious observance in the USA: Findings from the 2000-01 National Jewish Population Survey." Journal of Religion and Health 50 (2011): 852-68.

35. Jeff Levin. "Religion and positive well-being among Israeli and diaspora Jews: Findings from the World Values Survey." Mental Health, Religion \& Culture 15 (2012): 689-707.

36. Jeff Levin. "Religion and psychological well-being and distress in Israeli Jews: Findings from the Gallup World Poll.” Israel Journal of Psychiatry and Related Sciences 48 (2011): 252-61.

37. Jeff Levin. "Religious behavior, health, and well-being among Israeli Jews: Findings from the European Social Survey." Psychology of Religion and Spirituality, 2013, doi:10.1037/a0032601. Online prepublication.

38. Jeff Levin. "Religion and happiness among Israeli Jews: Findings from the ISSP Religion III Survey." Journal of Happiness Studies, 2013, doi:10.1007/s10902-013-9437-8. Online prepublication.

39. Jeff Levin. "Religion and physical health among older Israeli Jews: Findings from the SHAREIsrael Study." Israel Medical Association Journal 14 (2012): 595-601.

40. Jeff Levin. "Religion and mental health among Israeli Jews: Findings from the SHARE-Israel Study." Social Indicators Research 113 (2013): 769-84.

41. Charles S. Kamen. "'Quality of life' research at the Israel Central Bureau of Statistics: Social indicators and social surveys." Social Indicators Research 58 (2002): 141-62.

42. Bernard M.S. Van Praag, Dmitri Romanov, and Ada Ferrer-i-Carbonell. "Happiness and financial satisfaction in Israel: Effects of religiosity, ethnicity, and war." Journal of Economic Psychology 31 (2010): 1008-20.

43. Jeff Levin. "Religion and mental health: Theory and research." International Journal of Applied Psychoanalytic Research 7 (2010): 102-15.

44. Sergei A. Kharitonov. "Religious and spiritual biomarkers in both health and disease." Religions 3 (2012): 467-97.

45. Ellen L. Idler, and Stanislav V. Kasl. "Religion among disabled and nondisabled persons II: Attendance at religious services as a predictor of the course of disability." Journal of Gerontology: Social Sciences 52B (1997): S306-16.

46. Isaac W. Eberstein, and Kathleen M. Heyman. "Jewish Identity and Self-Reported Health." In Religion, Families, and Health: Population-Based Research in the United States. Edited by Christopher G. Ellison and Robert A. Hummer. New Brunswick: Rutgers University Press, 2010, pp. 349-67.

47. Israel Central Bureau of Statistics. "Methodology." Available online: http://geobase.huji.ac.il/ catalog-docs/f788_2009Methodology.pdf (accessed on 12 September 2013).

48. Israel Social Sciences Data Center. "Israel Social Survey 2009." Available online: http://geobase.huji.ac.il:8080/catalog/?dataset=0788 (accessed on 12 September 2013).

49. A. Ponizovsky, Y. Ginath, R. Durst, B. Wondimeneh, S. Safro, S. Minuchin-Itzigson, and M. Ritsner. "Psychological distress among Ethiopian and Russian Jewish immigrants to Israel: A cross-cultural study." International Journal of Social Psychiatry 44 (1998): 35-45.

50. Anshel Pfeffer. "Judaism without labels." Haaretz, 24 September 2010. Available online: http://www.haaretz.com/print-edition/news/judaism-without-labels-1.315377 (accessed on 12 September 2013). 
51. Ann Bowling. "Measures of Life Satisfaction and Morale." In Measuring Health: A Review of Quality of Life Measurement Scales, 2nd ed. Buckingham: Open University Press, 1997, pp. 111-27.

(C) 2013 by the author; licensee MDPI, Basel, Switzerland. This article is an open access article distributed under the terms and conditions of the Creative Commons Attribution license (http://creativecommons.org/licenses/by/3.0/). 